\title{
Colonic ischaemia as a severe Shiga toxin/verotoxin producing Escherichia coli O104:H4 complication in a patient without haemolytic uraemic syndrome, Germany, June 2011
}

S Cordesmeyer (s.cordesmeyer@raphaelsklinik.de) ${ }^{1}$, U Peitz² ${ }^{2}$ N Gödde ${ }^{3}$, H U Kasper ${ }^{4}$, M W Hoffmann ${ }^{1}$, E Allemeyer ${ }^{1,5}$

1. Department of General and Visceral Surgery, Raphaelsklinik Münster, Germany

2. Department of Gastroenterology, Raphaelsklinik Münster, Germany

3. Department of Anestesiology, Raphaelsklinik Münster, Germany

4. Institute of Pathology Medical Center, Münster, Germany

5. Division of Coloproctology, Raphaelsklinik Münster, Germany

Citation style for this article:

Cordesmeyer S, Peitz U, Gödde N, Kasper HU, Hoffmann MW, Allemeyer E. Colonic ischaemia as a severe Shiga toxin/verotoxin producing Escherichia coli O104:H4 complication in a patient without haemolytic uraemic syndrome, Germany, June 2011.

Euro Surveill. 2011;16(25): pii=19895. Available online: http://www.eurosurveillance.org/ViewArticle.aspx?Articleld=19895

An increasing rate of infections with Shiga toxin/verotoxin-producing Escherichia coli (STEC/VTEC) 0104: 4 has been observed in Germany since May 2011, with unusually high numbers of patients suffering from haemolytic uraemic syndrome (HUS). We report a STEC/VTEC 0104:H4 case without HUS, presenting with colonic ischaemia demanding surgery. This atypical clinical presentation of STEC $0104: \mathrm{H}_{4}$ infection might indicate new severe complications associated with this uncommon strain, and highlights the importance of immediate interdisciplinary assessment of STEC/VTEC patients.

\section{Clinical presentation and initial evaluation} A woman in her 80 s presented to our Emergency Department on 1 June with increasing abdominal pain and a history of nausea, primarily associated with dysuria that had been lasting for five days. On 29 May, the day after the onset of those symptoms, non-bloody diarrhoea had followed. The initial physical examination showed a mildly distended abdomen with diffuse pain and left upper quadrant tenderness without rebound. Blood tests showed a massive elevation of white blood cell count $(29,300 / \mu l$; normal range: $4,300-10,000 / \mu \mathrm{l}$ ) as well as an elevation of both C-reactive protein $(32.42 \mathrm{mg} / \mathrm{dl}$; normal range: $<0.5 \mathrm{mg} / \mathrm{dl})$ and lactate $(2.5 \mathrm{mmol} / \mathrm{l}$; normal range: $0.5-2.4 \mathrm{mmol} / \mathrm{l})$. Ultrasound and computed tomography $(\mathrm{CT})$ scans of the abdomen revealed distinctive amounts of ascites and wall thickening of parts of the transverse and descending colon, but did not show any disturbance of the main arteries and veins. Considering pseudomembranous colitis as a differential diagnosis, we decided to perform a colonoscopy.

The endoscopy showed a normal rectum and sigmoid colon, macroscopically. The descending colon had a circularly swollen, partly pale, partly bluish mucosa, with no evidence of bleeding after biopsy, a combination of symptoms highly suspicious of ischaemia (Figure 1).

\section{Surgical intervention}

Following the confirmation of ischaemia by endoscopy of the descending colon on 1 June, surgery was performed immediately. Non-occlusive ischaemia of the descending colon with gangrenous bowel wall was detected during the operation, with patent macroperfusion of the medial colic artery and inferior mesenteric artery arcade, as well as the left colic artery up to the

\section{FIGURE 1}

Circularly swollen, partly pale, partly bluish mucosa of the descending colon, highly suspicious of ischaemia, endoscopy of STEC/VTEC O104:H4 patient, Germany, June 2011

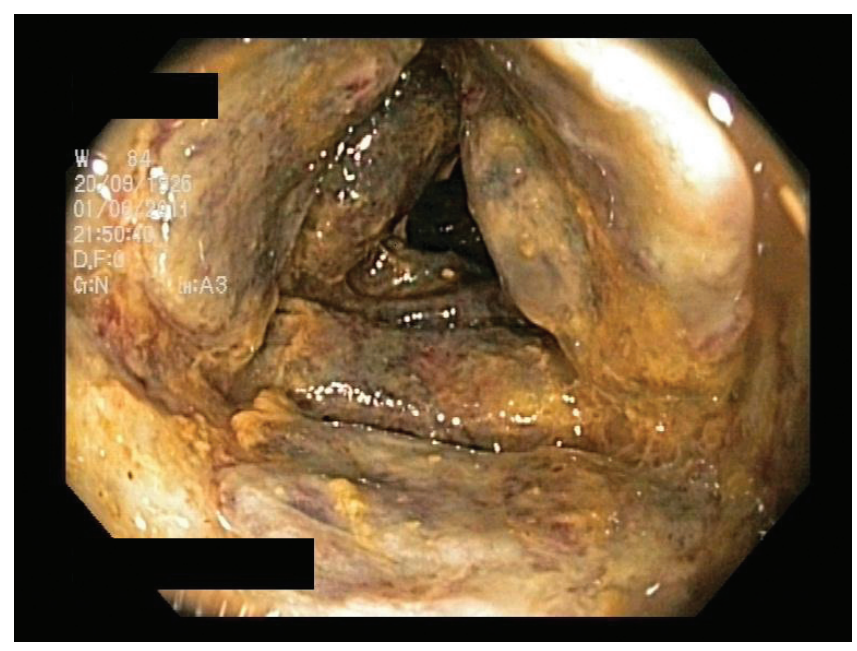

STEC/VTEC: Shiga toxin/verotoxin-producing Escherichia coli. 
gangrenous bowel wall. Therefore, a left hemicolectomy was performed, followed by thorough abdominal irrigation.

\section{Pathology}

Pathological examination of the removed part of the colon revealed wall thickening up to $1 \mathrm{~cm}$ and extensive necrosis throughout the entire intestinal wall with fibrinous-purulent exudation. The border area showed vital mucosa with erosive and phlegmonous inflammation, membranous-like fibrin exudation and crypt destruction, consistent with an ischaemic origin (Figures 2 and 3).

\section{Postoperative course}

After the operation, which occurred late in the evening on 1 June, the patient was admitted to the intensive care unit. The next morning, as a precautionary measure, due to the ongoing Shiga toxin/verotoxin-producing Escherichia coli (STEC/VTEC) 0104:H4 outbreak in Germany, the patient was placed in isolation and a stool sample was sent for further evaluation. The second day after surgery, seven days after the onset of the initial abdominal symptoms, neurological impairments were observed in terms of decelerated reactions of the patient, lack of orientation and intermittent response when addressed. Clinical examination was uneventful for abdominal, respiratory and haemodynamic findings. Laboratory studies were not suspicious for haemolytic uraemic syndrome (HUS): creatinine, elevated up to $1.7 \mathrm{mg} / \mathrm{dl}$ at admission (normal range: $<1.2 \mathrm{mg} /$ $\mathrm{dl})$, had immediately revealed decreasing tendencies (o.8 mg/dl at day four) after intravenous fluid application, and was therefore most likely due to diarrhoeainduced hypovolemia. Lactate dehydrogenase (LDH) ranged between $139 \mathrm{U} / \mathrm{l}$ (normal range: 135-225 U/l) at admission and $318 \mathrm{U} / \mathrm{l}$ six days after, whereas platelets always presented within normal limits. The patient was monitored closely and improved neurologically during the next day. During the following 48 hours, however,

\section{FIGURE 2}

Left hemicolectomy specimen, revealing wall thickening up to $1 \mathrm{~cm}$ with induration and increased fragility, STEC/ VTEC O104:H4 patient, Germany, June 2011

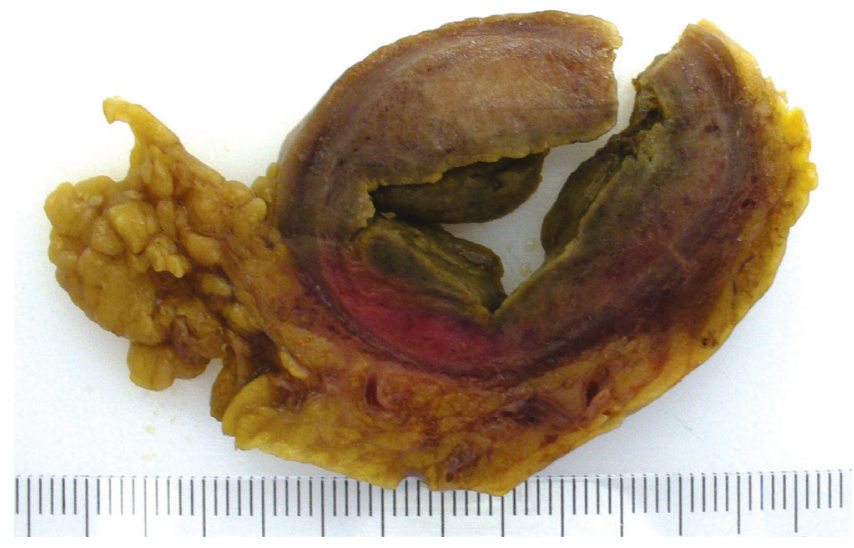

STEC/VTEC: Shiga toxin/verotoxin-producing Escherichia coli. noticeable neurological deficiencies with disturbance of vigilance, aphasia and apraxia were observed, as well as myoclonia of the extremities. Seizures did not occur. PCR analysis of the stool samples confirmed Shiga toxin 2-producing $E$. coli consistent with the strain responsible for the current outbreak, $\mathrm{O}_{104}: \mathrm{H}_{4}$, on 6 June. Monitoring the patient for an onset of HUS continued but has not eventuated as of 21 June.

\section{Discussion}

The ongoing outbreak of infections with STEC/VTEC, also commonly referred to as enterohaemorrhagic $E$. coli (EHEC), in Germany is one of the largest worldwide [1]. Besides causing non-bloody and bloody diarrhoea, the STEC/VTEC subtypes may also lead to HUS, a severe complication that is characterised by thrombocytopenia, microangiopathic haemolytic anaemia, and decreased renal function. So far, E. coli $\mathrm{O}_{157}: \mathrm{H}_{7}$ had been described as the predominant serotype causing HUS in approximately $10 \%$ of all cases to date $[2,3]$, whereas the strain responsible for the current outbreak, which has been identified as E. coli $0104: \mathrm{H}_{4}$, is an extremely rare strain, hardly described during the last decade [4]. With adults and predominantly women being infected, the age and sex distribution in the ongoing outbreak is unusual, but might be related to gender-specific differences in dietary habits: vegetables, which are generally more often consumed by women, are still suspected to have been contaminated and at the source of this outbreak. In addition, an unusually high number of patients have developed HUS: The latest data account for 814 patients with HUS from a total of 3,587 infected patients in Germany [1]. Neurological complications, which were seen, on average, in about $25 \%$ of HUS patients in former outbreaks [2], could also be more severe in this outbreak. Indeed,

\section{FIGURE 3}

Extensive mucosal and submucosal necrosis affecting the muscular lining of the descending colon, with fibrinouspurulent exudation, left hemicolectomy specimen of STEC/ VTEC O104:H4 patient, Germany, June 2011

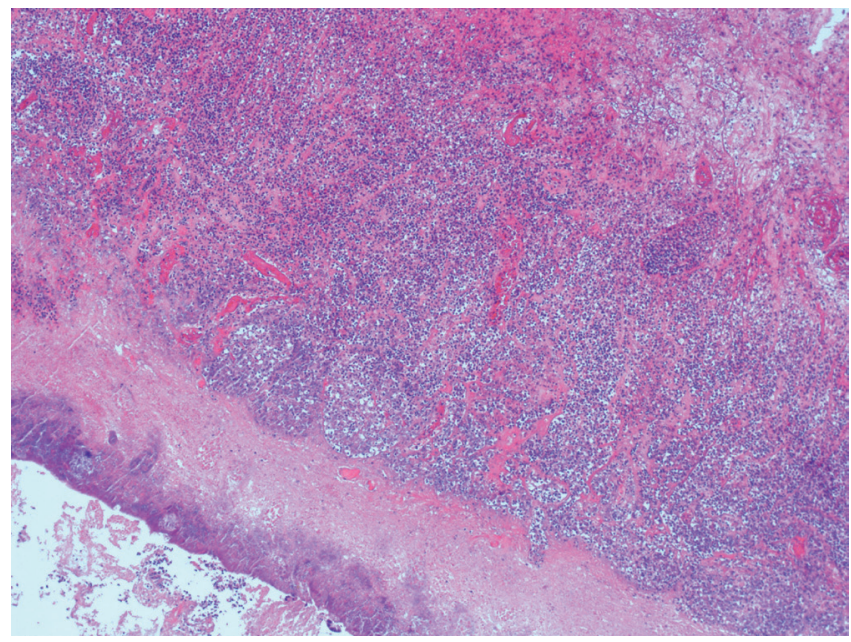

STEC/VTEC: Shiga toxin/verotoxin-producing Escherichia coli. 
the exchange among German clinicians, who set up a web-based platform to communicate clinical information in the context of the current outbreak, indicates higher numbers, but this has not been systematically evaluated so far. Taken together, the various aspects of the ongoing outbreak may suggest an increased virulent potential of the identified strain.

Besides HUS, STEC/VTEC-associated bowel ischaemia, as an additional severe complication, is rarely described in the literature. Very few reports of colonic necrosis and perforation due to Shiga toxin-induced intestinal damage exist, and in all these reports, this type of complication affected $E$. coli $0_{157}: \mathrm{H}_{7}$-infected individuals. This complication was moreover mostly encountered in paediatric patients with concomitant HUS [3]. Only one case of ischaemic colitis in a nonHUS adult has been previously described [5].

\section{Conclusion}

Besides leading to its major complication HUS, infection with STEC/VTEC 0104: $\mathrm{H}_{4}$ can also cause neurological complications and atypically present as bowel ischaemia, as shown in our patient. Since ischaemia-induced colonic wall thickening is difficult to differentiate from pseudomembranous colitis in CT imaging, endoscopy is essential and should be considered at an early diagnostic stage. Notably, our patient has not shown any signs of HUS to date, but obviously, even unexpected complications have to be considered as a differential diagnosis in STEC/VTEC $\mathrm{O}_{104}: \mathrm{H}_{4}$ infected patients, calling for interdisciplinary diagnostic investigations.

\section{References}

1. Informationen zum EHEC/HUS Ausbruchsgeschehen. [Information on the EHEC/HUS outbreak events]. Data from 20 Jun 2011, 3 pm. Berlin: Robert Koch Institut; 21 Jun 2011, $11 \mathrm{am}$. German. Available from: http://www.rki.de/cln_116/ nn_205760/DE/Home/Info-HUS.html

2. Enterohaemorrhagic Escherichia coli. Factsheet $\mathrm{N}^{\circ} 125$. Revised May 2005. World Health Organization. Geneva. Available from: http://www.who.int/mediacentre/factsheets/fs125/en/

3. Karch H, Tarr PI, Bielaszewska M. Enterohaemorrhagic Escherichia coli in human medicine. Int J Med Microbiol. 2005;295(6-7):405-18.

4. Scheutz F, Møller Nielsen E, Frimodt-Møller J, Boisen $\mathrm{N}$, Morabito S, Tozzoli R, et al. Characteristics of the enteroaggregative Shiga toxin/verotoxin-producing Escherichia coli $0104: \mathrm{H}_{4}$ strain causing the outbreak of haemolytic uraemic syndrome in Germany, May to June 2011. Euro Surveill. 2011;16(24):pii=19889. Available from: http://www. eurosurveillance.org/ViewArticle.aspx?Articleld=19889

5. Kravitz GR, Smith K, Wagstrom L. Colonic necrosis and perforation secondary to Escherichia coli $\mathrm{O}_{157: \mathrm{H}_{7}}$ gastroenteritis in an adult patient without hemolytic uremic syndrome. Clin Infect Dis 2002;35(9):e103-5. 